\title{
Ancient Chinese medical ethics and the four principles of biomedical ethics
}

\author{
Daniel Fu-Chang Tsai University of Manchester and National Taiwan University Hospital, Taiwan, Republic of
} China

\begin{abstract}
The four principles approach to biomedical ethics (4PBE) has, since the 1970s, been increasingly developed as a universal bioethics method. Despite its wide acceptance and popularity, the 4PBE has received many challenges to its cross-cultural plausibility. This paper first specifies the principles and characteristics of ancient Chinese medical ethics (ACME), then makes a comparison between ACME and the $4 P B E$ with a view to testing out the $4 P B E$ 's cross-cultural plausibility when applied to one particular but very extensive and prominent cultural context. The result shows that the concepts of respect for autonomy, non-maleficence, beneficence and justice are clearly identifiable in ACME. Yet, being influenced by certain socio-cultural factors, those applying the 4PBE in Chinese society may tend to adopt a "beneficence-oriented", rather than an "autonomy-oriented" approach, which, in general, is dissimilar to the practice of contemporary Western bioethics, where "autonomy often triumphs".
\end{abstract}

(Fournal of Medical Ethics 1999;25:315-321)

Keywords: Chinese medical ethics; principlism; autonomy

The four principles approach to biomedical ethics $^{1}$ (autonomy, beneficence, non-maleficence and justice, collectively known as the "principlesoriented framework" or "principlism") has been developed by Beauchamp and Childress in America since the 1970 s, and has been promoted by Raanan Gillon as the "four principles plus scope" approach in Europe. It has been popularly accepted, especially in medical circles, as a set of "universal" guidelines for bioethics, despite much vehement criticism. This approach claims, according to Gillon, that "whatever our personal philosophy, politics, religion, moral theory, or life stance, we will find no difficulty in committing ourselves to four prima facie moral principles plus a reflective concern about their scope of application. Moreover, these four principles, plus attention to their scope of application, encompass most of the moral issues that arise in health care". ${ }^{3}$ This claim of "universality" may be the theory's most important merit, because if these moral principles are transcultural and utilise the common moral language of different societies, they can be applied worldwide, thus fulfilling the need for a crosscultural, global bioethics methodology. However, perhaps ironically, it is also the most challenged position since critics hold that: [since] "applied ethics is a phenomenon of a particular culture, principlism cannot be accepted as the timeless and univocal norm for bioethics as it claims to be". In other words: "because the theory is developed from American common morality (and in reality only from a subset of that morality) it will mirror certain aspects of American society, and may, for this reason alone, be untransferable to other contexts and other societies". 5

Without entering into the many debates on principlism, this paper aims to compare ancient Chinese medical ethics (ACME) with the four principles of biomedical ethics (4PBE) and to test out the theory's cross-cultural plausibility in one particular but very extensive and prominent cultural context. The author will first specify the principles and characteristics of ACME, then assess whether the four principles exist in ACME and whether they are commensurable with this particular Eastern, Chinese ethos. Ancient Chinese medical ethics will then be interpreted in the light of the four principles to endow these ancient maxims with a modern spirit.

\section{The principles and characteristics of ancient Chinese medical ethics}

The earliest and most representative literature of medical ethics in China appeared in the seventh century. Sun Szu-miao (AD581-682), a famous physician, Taoist and alchemist, wrote a monograph entitled $O n$ the absolute sincerity of great physicians. ${ }^{6} \mathrm{He}$ emphasised the necessity of a thorough education, rigorous conscientiousness and self-discipline, and explained that "compassion ( $t z^{\prime} u$ )" and "humaneness (jen)" were the basic values of medical practice. In summarising his work, it could be concluded that the principles of medical ethics are as follows: 
THE PURPOSE OF MEDICAL PRACTICE

1. The object is to help, not to gain material goods.

2. Save life and do not kill any living creature.

3. Do not seek fame: virtuous conduct will be rewarded by humans and spirits.

THE REQUIREMENTS OF A GREAT PHYSICIAN

4. Master the foundations of medicine thoroughly, work energetically and unceasingly.

5. Be mentally calm and firm in disposition; do not give way to selfish wishes and desire.

6. Commit oneself with great compassion to save every living creature.

MANNER OF MEDICAL PRACTICE

7. Possess a clear mind and maintain a dignified appearance.

8. Do not be talkative, engage in provocative speech, or make fun of others.

9. Do not ponder upon self-interest and fortune; sympathise and help wholeheartedly.

10. Examine and diagnose carefully, prescribe accurately and cure effectively.

ATTITUDE TOWARDS PATIENTS

11. Treat everyone on an equal basis, no matter whether they are rich or poor.

12. Do not reject or despise a patient who suffers from abominable diseases such as ulcers and diarrhoea: be compassionate and sympathetic.

13. Do not enjoy oneself in a patient's house while the patient is suffering.

ATTITUDE TOWARDS OTHER PHYSICIANS

14. Do not belittle another physician in order to exalt one's own virtue.

15. Do not discuss others and decide about their rights and wrongs.

These moral doctrines emphasise the obligation to help as well as the virtuous character required of a physician. They also revealed that Confucian ideology was the underlying paradigm, with Taoism and Buddhism playing some part in providing immanent values.

After Sun Szu-miao, literature concerning the ethics of medical practice and the moral character of physicians appeared sporadically from time to time. The most relevant and important works include: Chu Hui-ming's (AD1590) Tou chen chuan hsin lu (Medical cures learnt by heart), ${ }^{7}$ Kung Hsin's (AD1556) Ming $i$ jen (Exhortation for enlightened physicians), ${ }^{8}$ Kung Ting-Hsien's (AD1615) Ten maxims for physicians and ten maxims for patients in Wan-ping hui-ch'un (Back to life from a myriad of sickness), ${ }^{9}$ Chen Shih-kung's (AD1605) Five commandments and ten requirements for physicians in Wai-ko cheng-tsung ( $A$ n orthodox manual of surgery), ${ }^{10}$ Chang-Lu's
(AD1627-1707) Ten commandments for physi: cians in Chang-shih-i-tung (Chang's gener $\overline{\text { h }}$ medicine), ${ }^{11}$ and so on. These articles cannot be addressed in detail here, but the author will refep to them in the following discussion.

On reviewing these ancient literatures concern ing medical ethics, we find that they have much i $\frac{\mathrm{F}}{\mathrm{g}}$ common and can be summed up in the following principles:

To appreciate the value of life and practise medi= cine with a heart of compassion and humaneeg

To master Confucianism prior to learning medi cine.

To master medical knowledge by studying relit able sources diligently and extensively.

To improve clinical skill and maintain a higg professional standard.

To be frugal, not to be greedy for wealth an fame.

To treat patients equally, and as if they were yoư family.

To be sincere, decorous, devoted, absorbed an selfless in treating patients.

To treat female patients only in the presence of a attendant; respecting their confidentiality, an not being lustful.

To be modest and prudent towards other phys $\stackrel{\mathbb{8}}{8}$ cians, not to belittle and criticise one colleagues.

These principles demonstrate ACME with the following characteristics:

1. Ancient Chinese medical ethics is establishe on the foundation of Confucian ethics: For tw8 thousand five hundred years, the Confucia scriptures were essential teaching materials fog students and Confucian ethics was the dom nant moral philosophy and ideology of Chinese. culture. Many Confucian scholars practised healing arts and formulated their professional ethics on the bases of Confucian ethics. Mede cal practice was regarded as one of their many duties. The moral standard for a physician was basically the same as that of an ideal Confuciae person, "chun-tzu": the "superior man". It wa widely accepted that a physician's saving his patients' lives and promoting their welfare was as respectable as a Confucian scholar's realisi ing his moral and political aspirations througef ruling the states and bringing peace and prose perity to people. The well-known saying. "gong-tong-liang-hsiang" ("the achievemeng equals that of a good prime minister) 
frequently used by Chinese people to praise a successful physician, reflects this concept exactly.

2. Humaneness (jen) is at the heart of its principles: Humaneness (jen) has appeared repeatedly in ACME. Confucius's concept of humaneness (jen) is bi-directional: the particular virtue which means love or benevolence, and the general virtue which is the foundation of morality, the basis of all goodness and the origin of all virtues; hence it is also rendered "perfect virtue" or "true humanity". ${ }^{2}$ The practice of medicine is the realisation of humaneness. This is why Chinese use the adage "jen-hsin-jen-shu" ("a heart of humaneness, the skill of humaneness") to extol the merits of good physicians; because it is the immanent character of humaneness that makes medical practice valuable and respectable.

3. Ancient Chinese medical ethics has a strong deontological feature: ACME reveals the nature of duty-based ethics by its emphasis on the physicians' responsibility to care for and help their patients and not to seek for profits and fame or to give way to selfish wishes and desires.

4. Ancient Chinese medical ethics appears to be a virtue-based ethics: Confucian philosophy holds that the moral cultivation of an individual is the key to the achievement of social order and the flourishing of human beings. If physicians cultivate virtue this will guarantee their medical practice is ethical. Humaneness, compassion, righteousness, sincerity, trustfulness, modesty, frugality, restraint, diligence, selflessness, determination, wisdom . . . etc appear repeatedly in codes of ACME, which seems to reveal its assumption that "only a virtuous physician is a good physician". Another adage, "shu-der-kan-chong" ("both skill and virtue are admirable"), popularly used to praise doctors, reveals the indispensability of "medical virtue" ("i-der").

For one thousand three hundred years, after the time of Sun Szu-miao, ACME was based on Confucian ethics. Chinese physicians, together with those who practised healing arts, were respected as highly as the Confucian politicians who were able to accomplish their aspiration to bring peace and prosperity to people; they were also expected to be so virtuous as to achieve the moral standard of an ideal Confucian person, "chun-tzu", the "superior man". Medical virtue has been the focus of Chinese physicians' daily practice, and humaneness (jen) is the name of the virtue.

\section{The four principles in ACME}

RESPECT FOR AUTONOMY

Autonomy literally means self-rule or selfgovernance; it implies that one can freely act according to one's own chosen plans. The principle of respect for autonomy involves "respectful attitude" as well as "respectful action". That is, it is to be acknowledged that every individual has the right to hold views, make choices and take actions based on personal values and beliefs. Furthermore, the individual's autonomous actions should not be subject to constraints by others so long as no serious harm be inflicted on other persons. ${ }^{13}$ The concept of autonomy is a relatively modern ethical ideal; in fact, even American medical history itself only developed an autonomy-based ethics in the last thirty years. We may hence not expect to find many documents concerning "respect for autonomy" in ACME, especially when the ancient Chinese Empire was basically a society of classes, aristocracy, patriarchy and paternalism. Yet, with careful examination and a reasonable and, it is to be hoped, not strained, interpretation, documented respect for autonomy can be discerned.

The concept of respect for autonomy in ACME is relevant to Kant's moral justification. One of Kant's supreme moral laws indicates that no person should be treated merely as a means but always also as an end. From the Kantian viewpoint, persons are free, equal and rational beings, intrinsically possessed of absolute moral value. This unconditional worth and capacity for self-determination is the fundamental reason why persons should be respected. Since Kant believed that "autonomy of will" was the distinctive feature of a person, thus it was through acts of rational choice that a person affirmed his/her dignity and sublimity, which is the highest side of human nature. To violate a person's autonomy is to prevent him from pursuing his own goals and determining his own destiny; therefore, it is to treat that person merely as a means of others rather than an end in himself.

Similarly, as John Harris has argued, the distinctive features of rationality, selfconsciousness and the capability of valuing one's own life, that a person has, make a person's life valuable. Valuable lives should be respected. Respect for the person is hence the starting point of morality and has two essential elements: first, concern for the welfare of others and second, respect for the wishes of others. ${ }^{14}$ Respect for autonomy is, therefore, the way in which one acknowledges other people as valuable beings of rationality and self-consciousness, the same as 
oneself, who are consequently entitled to make choices to direct their own destinies.

In Sun Szu-miao's work we find that there was a requirement for physicians to display a devoted and respectful attitude towards the patients as well as towards the medical profession. Physicians were not to give way to selfish desire and be concerned with themselves, but were to be concerned only with the welfare of their patients. This echoes the Kantian idea that patients should always be regarded as ends but not means. Sun Szu-miao required a strong will and self-discipline in physicians: characteristics which are comparable to Kant's "self-legislation" and autonomy. Moreover, the unconditional duty toward patients is in itself a form of categorical imperative. Sun wrote:

"He should always act as if he were thinking of himself. He should not desire anything and should ignore all consequences; he is not to ponder over his own fortune or misfortune and thus preserve life and have compassion for it. He should look upon those who have come to grief as if he himself had been struck, and he should sympathise with them deep in his mind. Neither dangerous mountain passes nor the time of day, neither weather conditions nor hunger, thirst nor fatigue should keep him from helping wholeheartedly." 15

$\mathrm{He}$ also advised against using living creatures, even a hen's eggs, as medication. This point of view, very likely influenced by the Buddhist precepts that "all living creatures are equal" and "do not kill life", showed a pervasive respect for life which is comparable to Albert Schweitzer's concept of "reverence for life". As Schweitzer wrote:

"... I am life wants to live in the midst of other life that wants to live. A thinking man feels compelled to approach all life with the same reverence he has for his own .... Ethics thus consists in this, that I experience the necessity of practising the same reverence for life toward all will to live, as toward my own. Therein lies the fundamental principle of morality." 16

One thousand years after Sun Szu-miao, Chu Hui-ming (AD1590), a Confucian scholar and medical practitioner, professed that physicians should reflect on each case very conscientiously and should not engage in deceitful practice. If the patient's prognosis was poor, the physician should say so at the very beginning so there would be no need to experience shame and reproach at the end. ${ }^{17}$ These warnings reflect the virtue of veracity and the rule of telling the truth.

Later on, Chen Shih-kung (AD1605) wrote his Five commandments and ten requirements to physicians and for the first time raised the concept of respect for the confidentiality of female patients:

"Physicians may visit a lady, widow or nun only the presence of an attendant, but not alone. The secret diseases of female patients should be exane ined with a right attitude, and should not be revealed to anybody, not even to the physiciands own wife." 18

To sum up, ACME requires doctors to hold respectful attitude and equal respect towards patients and to help patients with unremitting to even to the point of self-sacrifice. Ancient Chinese medical ethics also advocates the virtues sincerity, trustfulness, truthfulness and veracit that are correspondent to the principle of respee for autonomy. The medical ethics regarding respect for autonomy in these ancient Chinese classics is similar to the Kantian justification of treating persons as ends, not merely as means However, perhaps not surprisingly, we find nọ clear rules for "respecting the autonomout choice" of patients. Patient autonomy appeares nowhere in ACME, just as it wasn't present in the Western parallels: the Hippocratic oath, Percivalo ethics, and early codes of the American Medica Association or the World Medical Association Probably this is because patients always come to their doctors for a cure rather than with $\frac{9}{9}$ conscious concern that their autonomy be re spected. Yet undoubtedly, bearing a respectfut attitude towards persons is the foundation of an meaningful interpersonal relationship as well às the starting point of a good doctor-patien relationship, but this might not necessarily lead to a doctor respecting the autonomous choices of the patient. We may doubt that, in the ancierf Chinese ethos, patients' choices were respected b their doctors and families. The answer to whethes they were can only be arrived at from a broaders consideration of cultural factors and socia practice.

NON-MALEFICENCE

The principle of non-maleficence asserts that one ought not to inflict evil, harm or "risk of harm" of others. Therefore, health care professionals provide ing medical services that reach "the standard of due care" through proper training, competent skills and diligent practice can be regarded as fub filling the obligation of non-maleficence. ${ }^{19}$ Hence in the author's summarised principles of ACME "to master medical knowledge by studying reliable sources diligently and extensively", and "to improve clinical skill and maintain a high profes sional standard", are equivalent to the concept 
standard of due care. At the character and motivation level, ACME requires doctors "to be frugal, not to be greedy for wealth and fame", and "not to be lustful": thus evil and harm may be precluded.

Sun Szu-miao's work asserted the principles "of saving life and not killing any living creature" and also described how diligent and devoted a "great physician" should be in treating his patients. In this way, he can avoid negligence. Moreover, the injunction "do not enjoy oneself in a patient's house while the patient is suffering,", is yet another example of the application of nonmaleficence:

"And then in visiting the sick, wherever beautiful silks and fabrics fill the eye, the physician is not allowed to look out for them either to the left or to the right. Where the sounds of string instruments and instruments of bamboo fill the ear, he should not evoke the impression that he delights in them ... . Such manners have their origin in the assumption that if one single guest is not contented, the whole party cannot be merry ... if a physician is tranquil and engrossed in merry thoughts, in addition to being conceited and complacent, this is shameful for any human frame of mind. Such conduct is not suitable to man and conceals the true meaning of medicine." 20

In Chang-Lu's (AD1627-1707) Chang-shih-i-tung (Chang's general medicine), he set out ten commandments for physicians to abstain from: 1 . acquiring evil habits; 2 . over self-confidence; 3 . strong prejudice; 4 . imitation or lack of initiative; 5. making careless diagnosis; 6 . practising magic healing; 7. treating the nobility and commoners similarly; ${ }^{21} 8$. neglecting poor patients; 9 . extorting high compensation from critical cases; 10 . criticising or slandering other physicians. ${ }^{22}$ These commandments admonish doctors to stick to the standard of due care by maintaining competent skills and prudent practice and to refrain from subjecting patients to the risk of harm. They interpret and specify the principle of nonmaleficence comprehensively.

\section{BENEFICENCE}

Beneficence refers to actions done for the benefit of others, and is closely associated with mercy, kindness, charity, altruism, love, benevolence and humanity. Without question, health care professionals have the obligation to promote the welfare of their patients; this has always been the keynote of both ancient and modern, Eastern or Western, medical ethics. Ancient Chinese medical ethics basically focuses its moral doctrines of beneficence on humaneness (jen) and compassion $(t ' z u)$. Sun Szu-miao's medical ethics professed that: "The object is to help, not to gain material goods", and a "great physician" should "commit himself with great compassion to save every living creature". Kung Hsin in AD1556 wrote: “The good physician of the present day cherishes humaneness and righteousness .... He cares not for vainglory, but is intent upon relieving suffering among all classes. He revives the dying and restores them to health: his beneficence is equal to that of Providence."23 Kung Ting-Hsien (AD1615) also said, in his Ten maxims for physicians, that: "Firstly, they should adopt a disposition of humaneness; this is a justified demand. They should make a very special effort to assist the people and to perform far-reaching good deeds." ${ }^{24}$ Ancient Chinese medical ethics urges physicians to "master Confucianism prior to learning medicine" and to practise medicine with compassion and humaneness. That is, they must regard their profession as a career of philanthropy, acting generously and selflessly to help the sick. From a Chinese maxim: "bo-ai ji-zhong" ("to relieve the great masses with philanthropy"), which was usually used to praise and encourage physicians, there is no doubt that both ACME and Confucius' ethics are very familiar with the principle of beneficence.

\section{JUSTICE}

Justice demands fair, equitable and appropriate treatment in the light of what is due or owed to persons. Injustice, therefore, means a wrongful act or omission that denies peoples their due benefits or fails to distribute burdens fairly. ${ }^{25}$ In the field of health care ethics, Gillon has interpreted the principle of justice as fair distribution of scarce resources (distributive justice), respect for people's rights (rights based justice), and respect for morally acceptable laws (legal justice). ${ }^{2}$ Since ACME consisted basically of physicians' in-group moral codes, justice in ACME refers to the idea that doctors should treat their patients equally, justly and righteously, rather than to distributive justice. Ancient Chinese medical ethics teaches that doctors should provide medical services indiscriminately to those who come to seek help, that is, they should provide equal access to medical care for everyone in need, but also provide special help to the poor. This concept appeared repeatedly in ACME, for example, Sun Szu-miao wrote :

"If someone seeks help because of illness or on the ground of another difficulty, [a great physician] should not pay attention to status, wealth or age, neither should he question whether the particular 
person is attractive or unattractive, whether he is an enemy or a friend, whether he is Chinese or a foreigner, or finally, whether he is uneducated or educated. He should meet everyone on equal ground." 26

Kung Hsin (AD1556) wrote that: "The good physician of the present day cherishes humaneness (jen) and righteousness (yi)". ${ }^{23} Y i$ generally means righteousness, appropriateness, and justice, which entails the meaning of "the right things to do" as well as "doing things right". Therefore, $y i$ is quite compatible with the principle of justice since the idea of justice contains "appropriate treatment towards people and affairs".

Chen Shih-kung (AD1605) also presented the similar idea of treating high or low, rich or poor equally. He particularly mentioned that prostitutes should be treated in the same way as daughters from a good family, which entails both equality and respect. Moreover: "Medicine should be given free to the poor. Extra financial help should be extended to the destitute patients; if possible. Without food, medicine alone cannot relieve the distress of a patient." 22

This refers to the principle that "inequality should exist to benefit the worst-off", which echoes Rawls's "difference principle" of justice ${ }^{27}$ as well as the principle of beneficence.

In summary, the principle of justice in ACME requires doctors to treat patients equally, and to extend compassion to the poor and the deprived and to afford them gratuitous service. Regarding the inter-physician relationship, ACME requires doctors "to be modest and prudent towards other physicians and not to belittle and criticise their colleagues", which might be considered a rule of fair competition.

\section{Conclusion}

From the above review, it can be seen that the concepts of the four principles are clearly identifiable in ACME. Beneficence and non-maleficence have always been the keynotes of ACME since humaneness (jen) is the central theme of Confucianism on which ACME was founded. Ancient Chinese medical ethics is also familiar with the concept of $y i$ (righteousness), equal treatment towards persons and extended help to the worst-off; therefore, it fulfils the concept of justice. Regarding the principle of respect for autonomy, ACME requires physicians to respect their patients as ends but not means by a sincere, decorous, devoted, absorbed and selfless attitude towards medical practice; it further requires them to value all life with a respectful attitude.
However, respecting a patient's autonomou choice was not mentioned explicitly.

The principles-oriented framework, which de fined the four principles to be prima facie binding duties without a priori ranking, ${ }^{28}$ provides no strategy for conflict resolution when these con $\frac{5}{5}$ peting principles clash. However, it show through the "specification", "balancing and ove? riding" of the principles, that it is possible develop coherent and justifiable answers to ethicat dilemmas. $^{29}$ But these processes are hugety influenced by social conventions and cultura values since medical practice is based on docto patient relationships which exist in a particula historical context. In the traditional Chinese cultural background, the emphasis on filial piety (Shiaw), family values and the common good maty cause individuals to sacrifice their right autonomous decision making to the preferential choice of families or social values. Putting the public interest before self-interest and individu요 rights, as well as highlighting the individus responsibility to the group may lead to collective ism or to the interpretation of justice, beneficen and non-maleficence in a "social-oriented" way, 30 which is very likely to suppress the concept of individual rights and autonomy. A more paterna istic and patriarchal historical tradition may evero tually lead the doctor-patient-family relationshir and medical decision making towards "medica paternalism". Therefore, the "beneficence oriented", rather than "autonomy-oriented" aps proach may be observed in the traditional style medical practice in Chinese society. This obviously contrary to the mainstream of contenos porary Western (or American) bioethics which, general, tends to grant the uppermost position to the "value-complex of individualism which unde? scores individual rights, privacy, autonomy and self-determination". ${ }^{31}$ Ancient Chinese medical ethics shares the same principles as contempora Western bioethics, but the outcome of the "spect fication", "balancing and overriding" could bof totally dissimilar since ACME chooses a different principle as the "predominant" or "overriding one.

What ACME can learn from the $4 \mathrm{PBE}$ is tha्f while it accords to the virtues of humaneness 9 paramount value, and while it accentuates the deontological feature of medical practice, and alse underlines personal responsibility to the societ] common good, individual rights and autonom should never be neglected or sacrificed. The traditional ethos of beneficence-orientation an social-orientation should be balanced by and re onciled with respecting individual rights an autonomy. For contemporary Western bioethies 
where "autonomy often triumphs", ${ }^{32}$ the virtue ethics approach of ACME, by emphasising the medical virtues of humaneness and compassion and a physician's duty to care with sincerity, devotion, and selflessness, might sound sermonising, old-fashioned and unrealistic. Yet, it is a timely reminder for the medical profession today, which has increasingly become either a product for profit-making in consumer-driven societies, or merely a public employment job within which doctors fulfil their daily routine but avoid giving personal or "directive" opinions in consultations since that could be considered manipulative or paternalistic. Ancient Chinese medical ethics calls to mind a precious element that exists in the ancient healing art, contemporary acceptance of which would stop the alienation between persons caused by overextended autonomy-oriented individualism and make the doctor-patient relationship meaningful again, namely, the art of humaneness.

\section{Acknowledgement}

The author would like to thank Professor John Harris for his inspiring comments on the earlier drafts of this paper.

Daniel Fu-Chang Tsai is an Attending Physician at the Department of Family Medicine, National Taiwan University Hospital, Taipei, Taiwan and currently a PhD student at the Centre for Social Ethics and Policy, University of Manchester.

\section{References and notes}

1 Beauchamp TL, Childress JF. Principles of biomedical ethics [4th ed]. New York: Oxford University Press, 1994.

2 Gillon R. Medical ethics: four principles plus attention to scope. British Medical fournal 1994; 309:184-8. See also Gillon R. Philosophical medical ethics. Chichester: John Wiley \& Sons, 1986, and Gillon R, Lloyd A, eds. Principles of health care ethics. Chichester: John Wiley \& Sons, 1994: part I.
3 See reference 2: British Medical fournal: 184.

4 DuBose ER, Hamel RP, O'connell LJ, eds. A matter of principles? - Ferments in US bioethics. Valley Forge, Pennsylvania: Trinity Press International, 1994: 6, 106.

5 Holm S. Not just autonomy - the principle of American biomedical ethics. Fournal of Medical Ethics 1995;21:332-8.

6 Unschuld PU. Medical ethics in Imperial China. London: University of California Press, 1979: 26-33. Primary source: Chen Meng-lei, et al. Ku-chin t'u-shu chi-ch'eng. Place and year of publication, not available. Publisher: Chung-hua shu-chu.

7 Primary source: Chu Hui-ming, Tou-chen chuan-hsin lu. In: Ch'eng Yung-pei, ed. Liu-li chai I-shi shih-chung. Canton: Tsang-huiu tang, 1981.

8 Primary source: Kung Hsin, Ming I fen. In: Chen Meng-lei, et al. Ku-chin t'u-shu chi-ch'eng, I-bu chuan-lu. Taipei: Yi-wen publishing company, 1958.

9 Primary source: Kung Ting-hsien. Wan-ping hui-chun. Shanghai: Ta-cheng shu-chu, 1925.

10 Primary source: Chen Shih-kung. Wai-ko cheng-tsung. Revised edition edited by Hsu Ta-chun. Shanghai: Hai-tso shu-chu, 1905.

11 Primary source: Chang Lu. Chang-shih I-tung. Shanghai: Ko-hsueh chi-shu chu-pan she, 1963.

12 The Confucian analects. In: Chen WT. $A$ source book in Chinese philosophy. New Jersey: Princeton University Press, 1969: 16, 40.

13 See reference 1: 120-7.

14 Harris J. The value of life. London: Routledge, 1985: 8-9.

15 See reference 6: 30-1.

16 Schweitzer A. Civilization and ethics [part II of The philosophy of civilization]. Translated by Naish J. London: Macmillan, 1929: 246-7.

17 See reference 6: 62-6.

18 Lee T. Medical ethics in ancient China. In: Veatch RM, ed. Cross cultural perspectives in medical ethics: readings. Boston: Jones and Bartlett, 1989: 134-6.

19 See reference $1: 189-95$.

20 See reference $6: 26-33$.

$21 \mathrm{He}$ believed that the physiques of the nobility and the commoners were different.

22 See reference 18: 136

23 See reference 18: 134 .

24 See reference 6: 70-6.

25 See reference 1: 327 .

26 See reference 6: $29-33$

27 Rawls J. A theory of justice. Cambridge, Massachusetts: Harvard University Press, 1971: 83.

28 Childress JF. Principle-oriented bioethics: an analysis and assessment from within. See reference 4: 73-98.

29 See reference 1: 28-37.

30 Yang KS. Social orientation and individual modernity among Chinese students in Taiwan. The fournal of Social Psychology 1981;113:159-70.

31 Fox RC. The evolution of American bioethics: a sociological perspective. In: Weisz G, ed. Social science perspectives on medical ethics. Philadelphia: University of Pennsylvania Press, 1991: 201-27.

32 See reference 31: 76. 